\title{
Size matters but hunger prevails - begging and provisioning rules in blue tit families
}

\author{
Nolwenn Fresneau ${ }^{1}$, Arne Iserbyt ${ }^{\text {Corresp., }}{ }^{1}$, Carsten Lucass ${ }^{1}{ }^{\text {, }}$, Wendt Müller ${ }^{1}$ \\ ${ }^{1}$ Department of Biology / Behavioural Ecology and Ecophysiology Group, Universiteit Antwerpen, Wilrijk, Antwerp, Belgium \\ Corresponding Author: Arne Iserbyt \\ Email address: arne.iserbyt@uantwerpen.be
}

It is commonly observed in many bird species that dependent offspring vigorously solicit for food transfers provided by their parents. However, the likelihood of receiving food does not only depend on the parental response, but also on the degree of sibling competition, at least in species where parents raise several offspring simultaneously. To date, little is known about whether and how individual offspring adjusts its begging strategy according to the entwined effects of need, state and competitive ability of itself and its siblings. We here manipulated the hunger levels of either the two heaviest or the two lightest blue tit (Cyanistes caeruleus) nestlings in a short-term food deprivation experiment. Our results showed that the lightest nestlings consistently begged more than the heaviest nestlings, an effect that was overruled by the tremendous increase in begging behaviour after food deprivation. The amplified begging signals after food deprivation were meanwhile the only cue for providing parents in their decision process. Furthermore, we observed flexible but state-independent begging behaviour in response to changes in sibling need. As opposed to our expectations, nestlings consistently increased their begging behaviour when confronted with food deprived siblings. Overall, our study highlights that individual begging primarily aims at increasing direct benefits, but nevertheless reflects the complexity of a young birds' family life, in addition to aspects of intrinsic need and state. 
1 Size matters but hunger prevails - begging and provisioning rules in blue tit families

2

3 Nolwenn Fresneau ${ }^{1}$, Arne Iserbyt ${ }^{1}$, Carsten Lucass ${ }^{1}$, Wendt Müller ${ }^{1}$

4

$5{ }^{1}$ Department of Biology, Behavioural Ecology and Ecophysiology Group, University of Antwerp,

6 Universiteitsplein 1, 2610 Antwerp, Wilrijk, Belgium

7

8 Corresponding Author:

9 Arne Iserbyt ${ }^{1}$

10

11 Email address: arne.iserbyt@uantwerpen.be 


\section{Abstract}

13 It is commonly observed in many bird species that dependent offspring vigorously solicit for food

14 transfers provided by their parents. However, the likelihood of receiving food does not only depend

15 on the parental response, but also on the degree of sibling competition, at least in species where

16 parents raise several offspring simultaneously. To date, little is known about whether and how

17 individual offspring adjusts its begging strategy according to the entwined effects of need, state

18 and competitive ability of itself and its siblings. We here manipulated the hunger levels of either

19 the two heaviest or the two lightest blue tit (Cyanistes caeruleus) nestlings in a short-term food

20 deprivation experiment. Our results showed that the lightest nestlings consistently begged more

21 than the heaviest nestlings, an effect that was overruled by the tremendous increase in begging

22 behaviour after food deprivation. The amplified begging signals after food deprivation were

23 meanwhile the only cue in our study for providing parents in their decision process. Furthermore,

24 we observed flexible but state-independent begging behaviour in response to changes in sibling

25 need. As opposed to our expectations, nestlings consistently increased their begging behaviour

26 when confronted with food deprived siblings. Overall, our study highlights that individual begging

27 primarily aims at increasing direct benefits, but nevertheless reflects the complexity of a young

28 birds' family life, in addition to aspects of intrinsic need and state. 


\section{Introduction}

31 Offspring begging behaviour is commonly thought to stimulate parents to provide care (Godfray 1991; Kilner and Johnstone 1997). Parents receive potentially cryptic information of offspring

33 need or state, and are supposed to adjust their feeding strategy accordingly (Kilner \& Johnstone, 1997; Godfray \& Johnstone, 2000). This is empirically supported by experimental studies showing an increase in parental provisioning in response to an increase in offspring begging (e.g. Mondloch, 1995; Dor \& Lotem, 2010; Royle, Smiseth \& Kölliker, 2012). However, offspring begging signals of need may no longer induce a parental response in unpredictable and poor environments, as parents in such conditions may preferentially feed offspring that signal good condition or quality (Caro et al., 2016). Parent-offspring communication may further be complicated by an evolutionary conflict of interest between parents and their young regarding the amount of provided food, with nestlings asking for more than is optimal for the parents to provide (parent-offspring conflict, Trivers, 1974). However, excessive offspring begging is constrained by the associated costs of displaying it, which may guarantee the honesty of the signal ("honest signalling theory": Maynard Smith, 1991; Johnstone \& Grafen, 1993). Such costs include reduced offspring development (Kilner, 2001), increased predation risk (Leech \& Leonard, 1997; Haskell, 2002) or physiological deterioration (Moreno-Rueda, 2010; Noguera et al., 2010; Moreno-Rueda \& Redondo, 2012; Soler et al., 2014). Given these fitness costs of begging, offspring are expected to optimize the intensity, duration and timing of their displays in order to maximize their gains.

However, receiving care does not only depend on the parents, at least not if an offspring is competing with sibling(s). Each offspring is expected to behave selfishly within its brood as it shares at best only half of its genes with each of its siblings (Trivers, 1974; Godfray, 1995a; 
53 Rodríguez-Gironés, Cotton \& Kacelnik, 1996; Mock \& Parker, 1997). Thus, the likelihood of

54 receiving care also depends on an individual's competitive ability, which is not necessarily equal

55 among individuals of the same brood. In birds for instance, hatching asynchrony creates a size

56 difference among nestlings (Cotton, Wright \& Kacelnik, 1999; Rodríguez-Gironés, Zúñiga \&

57 Redondo, 2002). Smaller nestlings may thus be outcompeted by their bigger and stronger

58 nestlings, resulting in accumulated long-term need (Oddie, 2000; Leonard, Horn \& Parks, 2003).

59 Thus the social environment that is shaped by all nestlings determines the outcome of competition

60 and, therewith, the cost-benefit ratio of a given begging strategy. For example, the likelihood of

61 receiving food may diminish when the nest is shared with hungry siblings. In this case, reducing

62 begging effort may avoid the costs of unrewarded begging. In summary, each nestling is expected

63 to adjust its begging behaviour according to both its own short- and long-term need, and according

64 to the intertwined effects of state, need and competitive abilities of its siblings (Price, Harvey \&

65 Ydenberg, 1996; Price, Ydenberg \& Daust, 2002). Experimental studies testing these predictions

66 are nearly absent from the scientific literature.

67

68 We here investigated whether and how blue tit (Cyanistes caeruleus) nestlings adjust their begging

69 behaviour according to their own and their siblings' hunger level, taking the hierarchical position

70 within the brood into account. Specifically, we manipulated the hunger level of two target nestlings

71 during a short-term (90 minutes) food deprivation experiment. These two nestlings were the

72 extreme positions within the brood hierarchy (i.e. either the two heaviest or the two lightest

73 nestlings), which are supposed to differ in competitive ability and long-term need (Price, Harvey

74 \& Ydenberg, 1996; Lotem, 1998; Cotton, Wright \& Kacelnik, 1999). We predict that increased

75 begging intensity by food-deprived nestlings should be accompanied by a decreased begging 
76 intensity from their siblings. Furthermore, we expect that the lightest siblings will be more

77 reluctant to withdraw from competition as their long-term need and, therefore, their intrinsic

78 motivation to access food, would be higher than the intrinsic motivation of heavier nestlings.

79 Under the assumption that begging, among others, is an honest signal of need in blue tits, we expect

80 a positive parental response to nestlings with experimentally exaggerated begging behaviour.

\section{Methods}

83 This experiment took place in May 2014 in a nest-box population of blue tits breeding in

84 Peerdsbos, a mature oak-beech forest in the north of Antwerp (N51 ${ }^{\circ} 16^{\prime}, \mathrm{E} 4^{\circ} 28^{\prime}$, Belgium). Nest

85 boxes were checked daily to determine laying date, clutch size, the onset of incubation and

86 hatching date (here defined as day 1). All nestlings within a nest hatched within 24 hours. Nestling

87 body mass was determined on day 12 . To enable individual recognition on the video recordings,

88 the two heaviest and the two lightest nestlings were marked with respectively a horizontal and

89 vertical line on the upper mandible of the beak, using a non-toxic black marker (Artline $(870 \mathrm{~N}$ ).

90 We are confident that this marking has very limited effect on parental behaviour, because the

91 markings become invisible from the parents' perspective when nestlings open their beak when

92 soliciting for food and thus presenting gape and mouth flange colouration (Heeb, Schwander \&

93 Faoro, 2003). The difference in body mass between the two heaviest and the two lightest nestlings

94 was on average $1.74 \pm 0.22 \mathrm{~g}$ (Mean $\pm \mathrm{SD}$ ). Infrared cameras (420TVL) were installed inside the nest-

95 box underneath the lid, facing downwards. This was done one day before the experiment, so that

96 the adults were already habituated to the camera (Lucass et al., 2016). The entire experiment was

97 video monitored and started by closing the entrance of the nest box with small iron bars for 30

98 minutes (Figure 1), which prevented parents from entering. This was done to reduce the 
99 behavioural bias due to feeding events prior to the behavioural measurements, and thus to make

100 hunger levels comparable within and across nests (e.g. Iserbyt et al., 2017). The nest entrance was

101 then reopened for another 30 minutes to monitor the parental feeding and nestling begging

102 duration. This period is referred to as the "Control" period before the food deprivation experiment

103 (Figure 1).

104 We then removed the two heaviest nestlings or the two lightest nestlings and food deprived (FD)

105 them for 90 minutes. We kept both nestlings in a cloth bag in an insulated box along with a hand

106 warmer. We replaced these nestlings with foster nestlings of similar mass from a neighbouring

107 nest box, to keep the brood size constant during the food deprivation period of the two focal

108 nestlings. Which nestlings (the two heaviest or lightest nestlings, respectively) were selected for

109 the food deprivation procedure was alternated across nests $\left(\mathrm{N}_{\text {lightest FD }}=15\right.$ nests; $\mathrm{N}_{\text {heaviest FD }}=15$

110 nests). Brood size of the experimental nests varied from 8 to 14 nestlings and did not differ between

111 both experimental groups.

112 After 90 minutes of food deprivation the focal nestlings were returned to their nest, and the foster

113 nestlings were returned to their own nest. We then repeated the procedure as detailed in the control

114 period (now "After FD" in Figure 1), i.e. parental feeding and nestling begging duration was

115 monitored after a 30 minute period with the nest entrance closed. This period was again necessary

116 to standardize hunger levels of the non-FD nestlings. The experiment was carried out in agreement

117 with Belgian and Flemish legislation and was approved by the Ethical Committee for animals

118 (ECD) of the University of Antwerp (license number 2011-10).

119 
120 Video analyses

121 All videos were analysed blinded and by the same person, using video analysis software

122 (NOLDUS Observer XT 10.0, The Netherlands). We quantified begging behaviour by measuring

123 the nestling gaping time, i.e. the time when the beak of the nestling is open. This begging duration

124 was measured from the moment that a parent entered the nest box, until the moment that one of

125 the nestlings was fed. In blue tits, parents typically provide one food item at a time, and begging

126 rapidly ceases once that item has been transferred. Furthermore, only the first two feeding visits

127 were considered, to assure that the brood was still at the experimentally manipulated hunger level.

128 Note that in case of the food deprivation each time only two nestlings were food deprived, either

129 the two heaviest or the two lightest nestlings. Unfortunately, it was not possible to distinguish

130 individual nestlings within its body mass rank during the video analyses. For each feeding visit,

131 behavioural data from both nestlings within the mass rank were therefore summed and analytically

132 considered as one individual (RankID, see below). This results in eight $\left(2^{3}\right)$ behavioural

133 observations per nest; i.e. two feeding events, two mass ranks (light and heavy) and two periods

134 (control and after FD; see Supplementary material). During provisioning, we scored which nestling

135 received the food item (one of both light, one of both heavy nestlings, or neither of the two groups;

1361 when fed and 0 when not fed).

\section{Data analyses}

139 The begging duration was $\log 10$ transformed to meet assumptions of normality and centred by

140 conversion to standardized (z) scores. However, we present mean values of the raw data (in 141 seconds \pm standard error) whenever useful. In four videos (3 Controls and 1 FD), neither of the 
142 parents returned to the nest within the 30 minutes of video recording and were therefore excluded

143 from the analysis.

144 A linear mixed effect (LME) model was used to test whether nestling begging duration during the

145 first two parental feeding bouts varied according to nestling context, nestling body mass rank

146 (heaviest or lightest), their interaction and brood size. The three possible nestling contexts were

147 "Control" (represents the individual status prior to the 90 minutes FD), "FD nestling" (status after

14890 minutes FD) and "Sibling of the FD nestling" (also after 90 minutes FD; Figure 2 and 3).

149 RankID (unique ID of the heaviest or lightest two nestlings within a nest) nested in NestID was

150 included as a random effect to account for pseudoreplication of non-independent data.

151 The probability of receiving food was analysed in a generalized linear mixed effect (GLME) model

152 with the variable "fed" $(1=$ fed and $0=$ not fed $)$ as a response variable using a binomial distribution

153 and a clog-log link (since there were more 0 than 1). RankID nested within NestID was used as a

154 random effect and nestling context, rank, their interaction and brood size were included as 155 explanatory variables.

156 In all cases, we performed stepwise backward model selection procedures starting from the full

157 model. We tested fixed effects in the models fitted with the maximum likelihood (ML) by 158 comparing a model with and without the fixed effect in question using likelihood ratio tests (LRT)

159 against a $\chi^{2}$ distribution. Non-significant fixed effects $(P$ value greater than 0.05$)$ were removed 160 one by one from the model starting with the least significant. For all variables not selected in the

161 final model we provide the $\chi^{2}$ value and the $P$ value associated with the model comparison analysis

162 in the results section. The final model was fitted with REML (Restricted Maximum Likelihood) to 163 obtain the coefficients for the fixed effects and variance estimates for the random effects (Zuur et 
164 al., 2009). All statistics were performed in R version 2.15.2 (R Development Core Team, 2012),

165 using the nlme package (Pinheiro et al., 2013) and the lme4 package (Bates et al., 2013).

166

167 Results

168 Nestling begging

169 Begging duration significantly differed according to the nestling context (Table 1). Nestlings

170 almost doubled their begging duration following food deprivation (Mean \pm SE; Control: $\mathrm{N}=84$,

$1712.37 \pm 0.28 \mathrm{sec}$; FD nestlings: $\mathrm{N}=50,4.52 \pm 0.60 \mathrm{sec}$; post-hoc test: $\chi^{2}=16.79, P<0.001$; Figure 2).

172 Interestingly, siblings of the food deprived nestlings significantly increased their begging duration

173 compared with the non-food deprived control period (Siblings of the FD nestlings: $\mathrm{N}=50$,

$1743.46 \pm 3.93 \mathrm{sec} ; \chi^{2}=4.03, P=0.045$; Figure 2). Food deprived nestlings tended to beg longer than

175 their siblings did at the same moment $\left(\chi^{2}=3.61, P=0.057\right.$; Figure 2$)$. Nestling begging duration was

176 also influenced by the body mass rank, with the lightest nestlings begging significantly longer than

177 the heaviest nestlings (lightest: $\mathrm{N}=42,3.89 \pm 0.36$; heaviest: $\mathrm{N}=42,2.62 \pm 0.37$ ), an effect that was

178 consistent across contexts (Table 1, Figure 2). Finally, begging duration significantly decreased

179 with brood size (estimate \pm SE: $-0.18 \pm 0.06$; Table 1)

180

\section{Parental provisioning}

182 Parents significantly adjusted their feeding strategy according to the nestling context (Table 1,

183 Figure 3). Food deprived nestlings received remarkably more prey items than their siblings

184 (respectively $\mathrm{N}=50,66.0 \%$; and $\mathrm{N}=50,12.0 \%$; post-hoc test: $\mathrm{z}=4.52, P<0.001$ ). Siblings did not

185 receive more food than before the food deprivation experiment $(\mathrm{N}=84,14.3 \% ; \mathrm{z}=0.36, P=0.72)$. 
186 Neither the body mass rank of the nestlings nor the brood size influenced parental feeding

187 decisions (Table 1, Figure 3).

188

189 Discussion

190

Begging in function of need and state

191 Ninety minutes of food deprivation drastically increased begging duration of blue tit nestlings.

192 Thus begging, as measured in this study, does carry information about short-term nutritional need

193 (Godfray, 1991), which also supports the concept of begging being a plastic trait (Kedar et al.,

194 2000). Furthermore, we found that the lightest two nestlings consistently begged longer than the

195 two heaviest nestlings (Price, Harvey \& Ydenberg, 1996; Bonisoli-Alquati et al., 2011), even when

196 hunger levels are comparable among nestlings. Such state-dependent begging behaviour has been

197 interpreted as a signal of long-term need (Price, Harvey \& Ydenberg, 1996). The lightest nestlings

198 may have suffered from an enduring backlog demand, because they were persistently outcompeted

199 by their heaviest siblings (Smith \& Montgomerie, 1991; Dearborn, 1998) or, alternatively, because

200 parents made the choice to feed better quality nestlings (but see further; Kilner, 1995; Moreno-

201 Rueda et al., 2007).

202

203

Begging in function of the social environment

204 Our main aim was to test whether and how nestlings adjust their signalling to aspects of their social 205 environment, that is their position in the body mass hierarchy and the hunger level of their siblings. We found that non-food deprived nestlings only adjusted their begging level according to the elevated hunger levels of their siblings, and not according to their own or their sibling's rank in 
208 the hierarchy. This result is in contrast to a previous studies reporting that less needy chicks

209 withdraw from competition if the chance of obtaining food and thus the cost-benefit ratio worsens

210 (Romano, Caprioli \& Boncoraglio, 2012). In this scenario, siblings of food deprived nestlings may

211 gain indirect benefits from their altruistic behaviour. Nestlings are therefore expected to negotiate

212 with their siblings about who should receive the next prey item (Roulin, Kölliker \& Richner, 2000).

213 However, this hypothesis is not supported by our findings, as we found the opposite pattern in our

214 study system. Specifically, siblings increased their begging when the two focal nestlings were food

215 deprived, although this did not affect the likelihood to obtain food. It is possible that we did not

216 find evidence for negotiation or altruistic behaviour because brood sizes of blue tits are larger (8-

21714 nestlings, in our population) than in barn owls (Tyto alba; 2-9 nestlings; Roulin, Kölliker \&

218 Richner, 2000) and barn swallows (Hirundo rustica; 3-7 nestlings; Romano, Caprioli \&

219 Boncoraglio, 2012), in which sibling negotiation has been reported. Scramble competition may

220 increase with the number of siblings and this makes it harder for each individual to receive food

221 (Smith \& Montgomerie, 1991; Leonard et al., 2000). Thus withdrawing from competition during

222 a feeding event in large broods may not substantially increase the chance of being fed in the next

223 feeding event.

\section{Parental response}

226 Food deprived nestlings begged vigorously, which largely improved the chance to be fed compared 227 with their nest mates. This indicates that parents respond positively to begging and thus short-term 228 need, which is (among others) a prerequisite for begging to evolve as an evolutionary stable 229 strategy in the case of honest signalling models (Godfray, 1995b). This finding is in line with a 230 number of previous studies (e.g. Cotton, Kacelnik \& Wright, 1996; Price, Harvey \& Ydenberg, 
231 1996; Lotem, 1998), and supports the function of offspring begging both in a signalling context as

232 well as in sibling competition (Royle, Hartley \& Parker, 2002). However, the lightest nestlings,

233 which on average begged more, did not receive more food. Our observed parental response is in

234 line with previous findings, indicating that younger nestlings beg more than their older siblings

235 but receive less or 'only' equal amounts of food (Lotem, 1998; Cotton, Wright \& Kacelnik, 1999).

236 This can be interpreted as a brood reduction strategy, given that hatching asynchrony permits

237 reduction of the cost of rearing marginal offspring and ultimately, in case of food shortage, to

238 reduce the brood size (Forbes \& Glassey, 2000).

\section{Conclusions}

241 Blue tit nestlings adjusted their begging in function of their own short-term need. They additionally

242 altered their begging according to (changes in) their social environment, i.e. the enhanced hunger

243 level of their nest mates. However, blue tit nestlings never withdrew from competition in favour

244 of needier siblings, despite their genetic relatedness and potential indirect fitness benefits they

245 could have gained from it. On the contrary, overall brood begging levels rather increased when a

246 subset of nestlings was food-deprived, suggesting higher within-brood sibling competition which

247 matches the assumptions of scramble competition models. Furthermore, we showed that the

248 position within the body mass hierarchy had a large influence on individual begging behaviour,

249 but that the behavioural adjustments to changes in need and the social environment itself are state-

250 independent. Ultimately, blue tit parents fed the hungriest nestling, which was the one begging the

251 most, independent of whether it was the heaviest or lightest nestling within the brood. Taken

252 together, individual begging strategies are fine-tuned to the complexity of a young birds' family

253 life, but primarily vary with intrinsic need. 


\section{Acknowledgments}

256 The authors wish to thank William and Petra Van Dieren and the Agentschap Natuur en Bos (ANB)

257 for providing electricity and facilities during field work. We thank Erik Matthysen for giving 258 access to his field site, Joris Elst for help with the practical work, April Ward for analysing videos 259 and Jamie MacLaren for improving the writing. The authors also wish to thank Gregorio Moreno260 Rueda, Douglas W. Mock and two anonymous reviewers for their comments on a previous version 261 of this manuscript.

\section{Reference}

Bates D., Maechler Martin., Bolker B., Walker S., Maechler M., Bolker B., Walker S., Maechler 265 Martin., Bolker B., Walker S. 2013. lme4: Linear mixed-effects models using "Eigen” and S4. CRAN Repository. DOI: 10.18637/jss.v067.i01.

Bonisoli-Alquati A., Boncoraglio G., Caprioli M., Saino N. 2011. Birth order, individual sex and sex of competitors determine the outcome of conflict among siblings over parental care. Proceedings of the Royal Society B - Biological Sciences 278:1273-1279. DOI: 10.1098/rspb.2010.1741.

271 Caro SM., Griffin AS., Hinde CA., West SA. 2016. Unpredictable environments lead to the 272 evolution of parental neglect in birds. Nature communications 7:1-10. DOI: 10.1038/ncomms 10985 .

274 Cotton PA., Kacelnik A., Wright J. 1996. Chick begging as a signal: are nestlings honest? 275 Behavioral Ecology 7:178-182. DOI: 10.1093/beheco/7.2.178.

276 Cotton PA., Wright J., Kacelnik A. 1999. Chick begging strategies in relation to brood hierarchies 

and hatching asynchrony. The American naturalist 153:412-420. DOI: 10.1086/303178.

278 Dearborn DC. 1998. Begging behavior and food acquisition by brown-headed cowbird nestlings. 279 Behavioral Ecology and Sociobiology 43:259-270. DOI: 10.1007/s002650050490.

280 Dor R., Lotem A. 2010. Parental effort and response to nestling begging in the house sparrow: 281 repeatability, heritability and parent-offspring co-evolution. Journal of Evolutionary Biology 282 23:1605-1612. DOI: 10.1111/j.1420-9101.2010.02023.x.

283 Forbes S., Glassey B. 2000. Asymmetric sibling rivalry and nestling growth in red-winged 284 blackbirds (Agelaius phoeniceus). Behavioral Ecology and Sociobiology 48:413-417. DOI: $285 \quad 10.1007 / \mathrm{s} 002650000239$.

286 Godfray HCJ. 1991. Signaling of need by offspring to their parents. Nature 352:328-330. DOI: $287 \quad 10.1038 / 352328 \mathrm{a} 0$.

288 Godfray HCJ. 1995a. Signaling of need between parents and young: Parent-offspring conflict and 289 sibling rivalry. American Naturalist 146:1-24. DOI: 10.1086/285784.

290 Godfray HCJ. 1995b. Evolutionary theory of parent-offspring conflict. Nature 376:133-138. DOI: $10.1038 / 376133 \mathrm{a} 0$.

292 Godfray HCJ., Johnstone RA. 2000. Begging and bleating: the evolution of parent-offspring 293 signalling. Philosophical Transactions of the Royal Society B: Biological Sciences 355:1581294 1591. DOI: $10.1098 /$ rstb.2000.0719.

295 Haskell DG. 2002. Begging behaviour and nest predation. In: Wright J, Leonard ML eds. The 296 Evolution of Begging: Competition, Cooperation and Communication. Kluwer Academic 297 Publishers, 163-172.

298 Heeb P., Schwander T., Faoro S. 2003. Nestling detectability affects parental feeding preferences 299 in a cavity-nesting bird. Animal Behaviour 66:637-642. DOI: 10.1006/anbe.2003.2238. 
300 Iserbyt A., Eens M., Baetens W., Vermeulen A., Müller W. 2017. Within- and between-individual

301 (co)variance partitioning reveals limited pleiotropic effects of testosterone on immune

302 function, sexual signaling and parental investment. Behavioral Ecology and Sociobiology

$303 \quad 71: 74$. DOI: $10.1007 / \mathrm{s} 00265-017-2308-2$.

304 Johnstone RA., Grafen A. 1993. Dishonesty and the handicap principle. Animal Behaviour 305 46:759-764. DOI: 10.1006/anbe.1993.1253.

306 Kedar H., Rodríguez-Gironés MA., Yedvab S., Winkler DW., Lotem A. 2000. Experimental 307 evidence for offspring learning in parent-offspring communication. Proceedings of the Royal $308 \quad$ Society B - Biological Sciences 267:1723-1727. DOI: 10.1098/rspb.2000.1201.

309 Kilner RM. 1995. When do canary parents respond to nestling signals of need? Proceedings of the 310 Royal Society B - Biological Sciences 260:343-348. DOI: 10.1098/rspb.1995.0102.

311 Kilner RM. 2001. A growth cost of begging in captive canary chicks. Proceedings of the National 312 Academy of Sciences of the United States of America 98:11394-11398.

313 Kilner RM., Johnstone RA. 1997. Begging the question are offspring solicitation behaviours 314 signals of need. TRENDS in Ecology \& Evolution 12:11-15.

315 Leech SM., Leonard ML. 1997. Begging and the risk of predation in nestling birds. Behavioral 316 Ecology 8:644-646. DOI: 10.1093/beheco/8.6.644.

317 Leonard ML., Horn AG., Gozna A., Ramen S. 2000. Brood size and begging intensity in nestling 318 birds. Behavioral Ecology 11:196-201. DOI: 10.1093/beheco/11.2.196.

319 Leonard ML., Horn AG., Parks E. 2003. The role of posturing and calling in the begging display 320 of nestling birds. Behavioral Ecology Socioiology 54:188-193. DOI: 10.1007/s00265-003$321 \quad$ 0626-z.

322 Lotem A. 1998. Differences in begging behaviour between barn swallow, Hirundo rustica, 
nestlings. Animal Behaviour 55:809-818. DOI: 10.1006/anbe.1997.0675.

324 Lucass C., Iserbyt A., Eens M., Müller W. 2016. Structural (UV) and carotenoid-based plumage

325 coloration - signals for parental investment? Ecology and Evolution 6:3269-3279. DOI:

$326 \quad 10.1002 /$ ece3.2107.

327 Maynard Smith J. 1991. Honest signalling: the Philip Sidney game. Animal Behaviour 42:1034328 1035. DOI: $10.1016 / \mathrm{s} 0003-3472(05) 80161-7$.

329 Mock DW., Parker GA. 1997. The Evolution of Sibling Rivalry. Oxford University Press.

330 Mondloch CJ. 1995. Chick hunger and begging affect parental allocation of feedings in pigeons.

331 Animal Behaviour 49:601-613. DOI: 10.1016/0003-3472(95)80193-6.

332 Moreno-Rueda G. 2010. An immunological cost of begging in house sparrow nestlings.

333 Proceedings of the Royal Society B - Biological Sciences 277:2083-2088. DOI:

$334 \quad 10.1098 / \mathrm{rspb} .2010 .0109$.

335 Moreno-Rueda G., Redondo T. 2012. Benefits of extra begging fail to compensate for 336 immunological costs in southern shrike (Lanius meridionalis) nestlings. PLoS ONE 7:e44647.

337 DOI: 10.1371 journal.pone.0044647.

338 Moreno-Rueda G., Soler M., Soler JJ., Gabriel Martinez J., Perez-Contreras T. 2007. Rules of food

339 allocation between nestlings of the black-billed magpie Pica pica, a species showing brood $340 \quad$ reduction. Ardeola 54:15-25.

341 Noguera JC., Morales J., Pérez C., Velando A. 2010. On the oxidative cost of begging: 342 Antioxidants enhance vocalizations in gull chicks. Behavioral Ecology 21:479-484. DOI: $343 \quad 10.1093 /$ beheco/arq005.

344 Oddie KR. 2000. Size matters: competition between male and female great tit offspring. Journal 345 of Animal Ecology 69:903-912. DOI: 10.1046/j.1365-2656.2000.00438.x. 
346 Pinheiro J., Bates D., DebRoy S., Sarkar D., R Development Core Team. 2013. nlme: Linear and

347 Nonlinear Mixed Effects Models. R package.

348 Price K., Harvey H., Ydenberg R. 1996. Begging tactics of nestling yellow-headed blackbirds,

349 Xanthocephalus xanthocephalus, in relation to need. Animal Behaviour 51:421-435. DOI:

$350 \quad 10.1006 /$ anbe. 1996.0039.

351 Price K., Ydenberg R., Daust D. 2002. State-dependent begging with asymmetries and costs: A 352 genetic algorithm approach. In: Wright J, Leonard ML eds. The Evolution of Begging: 353 Competition, Cooperation and Communication. Dordrecht: Kluwer Academic Publishers, 354 21-42. DOI: $10.1007 / 0-306-47660-6$.

355 R Development Core Team R. 2012. R: A Language and Environment for Statistical Computing.

356 R Foundation for Statistical Computing 1:409. DOI: 10.1007/978-3-540-74686-7.

357 Rodríguez-Gironés MA., Cotton P., Kacelnik A. 1996. The evolution of begging: signaling and 358 sibling competition. Proceedings of the National Academy of Sciences of the United States of 359 America 93:14637-14641. DOI: 10.1073/pnas.93.25.14637.

360 Rodríguez-Gironés MA., Zúñiga JM., Redondo T. 2002. Feeding experience and relative size 361 modify the begging strategies of nestlings. Behavioral Ecology 13:782-785. DOI: $362 \quad 10.1093 /$ beheco/13.6.782.

363 Romano A., Caprioli M., Boncoraglio G. 2012. With a little help from my kin: barn swallow 364 nestlings modulate solicitation of parental care according to nestmates' need. Journal of 365 Evolutionary Biology 25:1703-1710. DOI: 10.1111/j.1420-9101.2012.02571.x.

366 Roulin A., Kölliker M., Richner H. 2000. Barn owl (Tyto alba) siblings vocally negotiate 367 resources. Proceedings of the Royal Society B - Biological Sciences 267:459-63. DOI: $368 \quad 10.1098 /$ rspb.2000.1022. 
369 Royle NJ., Hartley IR., Parker G a. 2002. Begging for control: when are offspring solicitation

370 behaviours honest? Trends in Ecology \& Evolution 17:434-440. DOI: 10.1016/S0169$371 \quad 5347(02) 02565-X$.

372 Royle NJ., Smiseth PT., Kölliker M. 2012. The Evolution of Parental Care. Oxford University 373 Press.

374 Smith HG., Montgomerie R. 1991. Nestling american robins compete with siblings by begging. 375 Behavioral Ecology and Sociobiology 29:307-312. DOI: 10.1007/bf00163989.

376 Soler M., Ruiz-Raya F., Carra LG., Medina-Molina E., Ibáñez-Álamo JD., Martín-Gálvez D. 2014. 377 A long-term experimental study demonstrates the costs of begging that were not found over 378 the short term. PloS one 9:e111929. DOI: 10.1371/journal.pone.0111929.

379 Trivers RL. 1974. Parent-offspring conflict. American Zoologist 14:249-264. DOI: $380 \quad 10.1093 / \mathrm{icb} / 14.1 .249$.

381 Zuur AF., Ieno EN., Walker N., Saveliev AA., Smith GM. 2009. Mixed effects models and 382 extensions in ecology with $R$. New York: Springer. DOI: 10.1007/978-0-387-87458-6. 
Figure 1

Overview and timeline of the experimental design when nestlings were 12 days old.

FD indicates that either the two heaviest or two lightest nestlings are Food Deprived for 90 minutes.

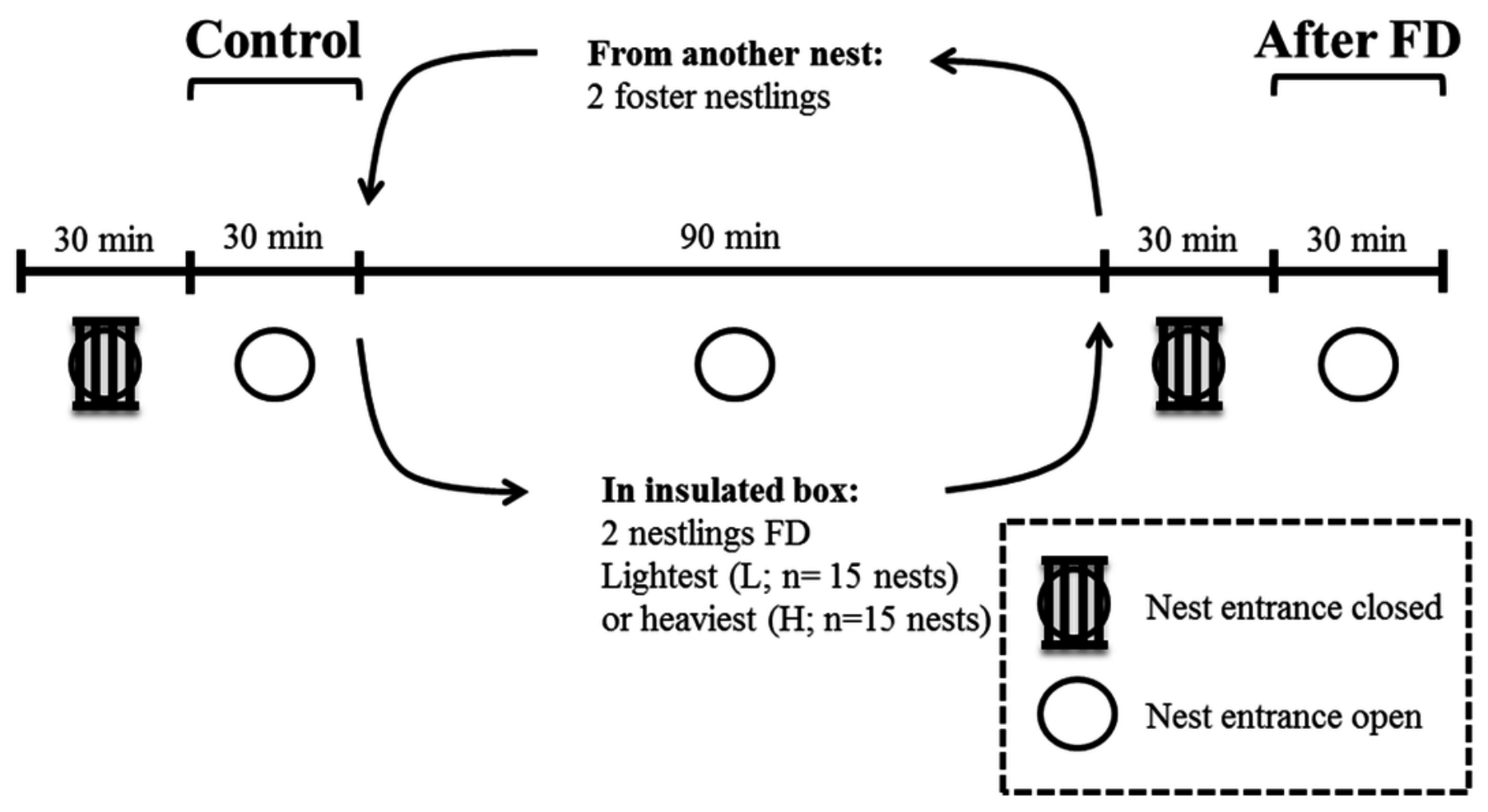




\section{Figure 2 (on next page)}

Mean ( $\pm \mathrm{SE}$ ) begging duration according to context and body mass rank.

The three contexts are Control (no nestlings are food deprived), FD nestlings (after 90 minutes of food deprivation) and siblings of the 90 minutes FD nestlings. Average values of the two heaviest and the two lightest nestlings are represented as respectively white and grey histograms. Post-hoc comparisons across contexts (heaviest and lightest nestlings combined) are represented with asterisks ( $P<0.05$; $* * P<0.01$; *** $P<0.001)$. $\mathrm{N}$ represents the number of experimental nests. 


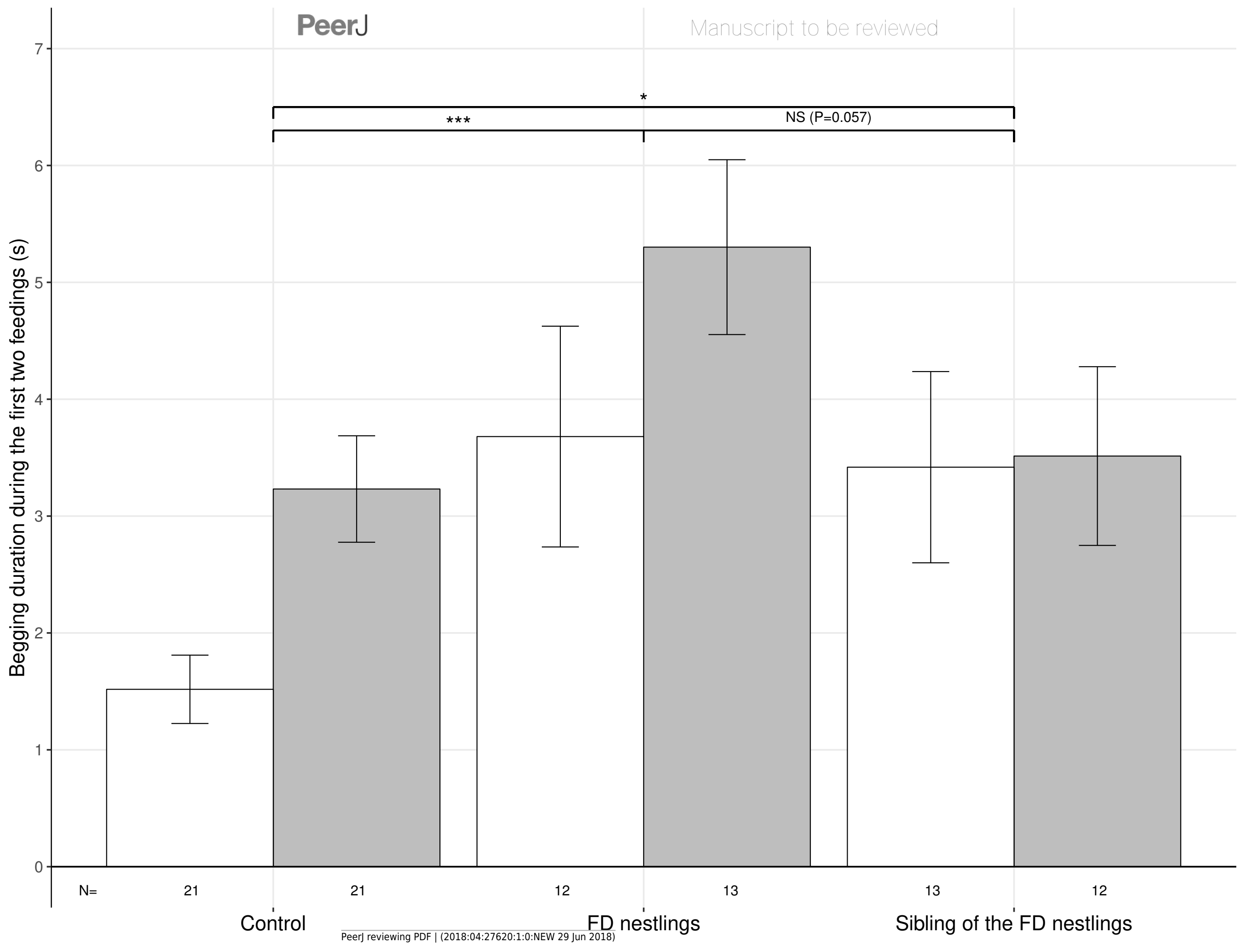




\section{Figure 3 (on next page)}

Mean ( \pm SE) proportion of parental feeds according to context and body mass rank.

Parental food transfers could be directed towards the two heaviest (white histograms), the two lightest (grey histograms) or non-focal nestlings. The contexts are Control (no nestlings are food deprived), FD nestlings (after 90 minutes of food deprivation) and Siblings of the 90 minutes FD nestlings. Post-hoc comparisons across contexts (heaviest and lightest nestlings combined) are represented with asterisks ( $P<0.05$; ** $P<0.01$; *** $P<0.001)$. N represents the number of experimental nests. 


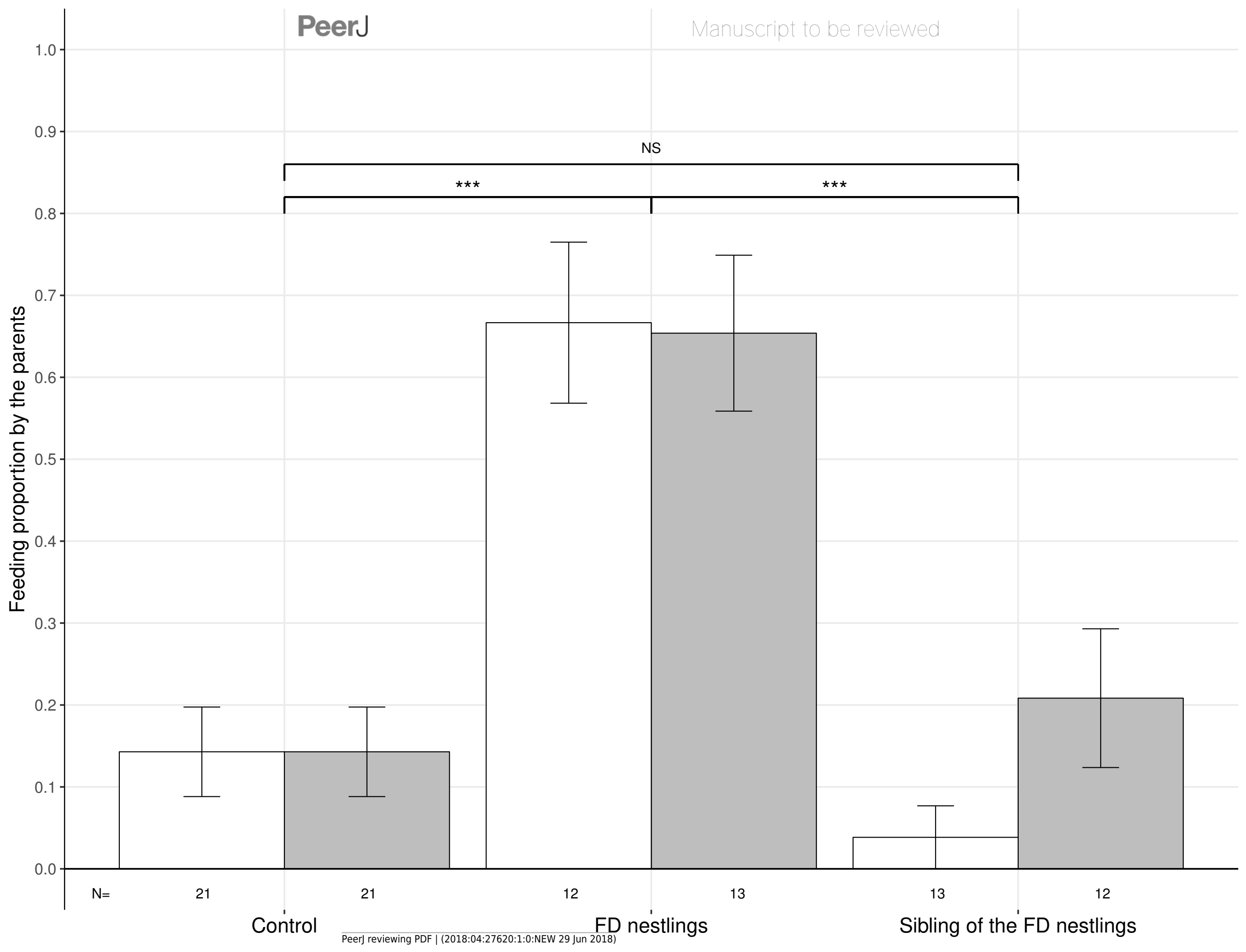




\section{Table $\mathbf{1}$ (on next page)}

Model comparisons exploring variation in nestling begging and parental provisioning behaviour.

Specifically, these models test the influence of the nestling context (Control, FD and Sibling FD), nestling body mass rank (heavy and light) and brood size on nestling begging duration (LME, a) and parental provisioning behaviour (GLME, b) during the first two parental feeding bouts. Nestling ID nested in Nest ID was included as a random effect. Each AIC value is based on a model that includes the respective variable, in addition to the variables situated under it in the table. Significant variables that were retained in the reduced model are highlighted in bold. 


\begin{tabular}{lcccc}
\hline Effect & df & AIC & LRT & P \\
\hline $\begin{array}{lccc}\text { (a) Nestling begging duration } \\
\text { Rank X Context }\end{array}$ & 2,128 & 512.5 & 3.5 & 0.17 \\
Brood size & $\mathbf{1 , 2 4}$ & $\mathbf{5 1 2 . 0}$ & $\mathbf{7 . 4 5}$ & $\mathbf{0 . 0 0 6}$ \\
Rank & $\mathbf{1 , 2 5}$ & $\mathbf{5 1 7 . 4}$ & $\mathbf{1 1 . 9 5}$ & $<\mathbf{0 . 0 0 1}$ \\
Context & $\mathbf{2 , 1 2 8}$ & $\mathbf{5 2 7 . 4}$ & $\mathbf{1 6 . 5 6}$ & $<\mathbf{0 . 0 0 1}$ \\
None & & 539.3 & & \\
(b) Parental provisioning & & & & \\
Brood size & - & 181.0 & 0.01 & 0.93 \\
Rank X context & - & 180.0 & 3.39 & 0.18 \\
Rank & - & 178.8 & 0.38 & 0.54 \\
Context & - & $\mathbf{2 2 0 . 7}$ & $\mathbf{4 5 . 8}$ & $<\mathbf{0 . 0 0 1}$ \\
None & - & 178.8 & - & -
\end{tabular}

